\title{
Influence of different air supply parameters on indoor thermal comfort of upper air supply room
}

\author{
Yan Wang ${ }^{1, *}$, and Zhuangzhuang $\mathrm{Qu}^{1}$ \\ ${ }^{1}$ Shandong Huayu Institute of technology, R \& D center of building energy saving engineering technology, Dezhou City, Shandong \\ Province
}

\begin{abstract}
With the help of Airpak software, the evaluation indexes of temperature field, velocity field and PMV under different air supply parameters are explored. Through the analysis of different parameters of the air supply field, such as temperature and PMV, the evaluation index of the optimal air supply field was established. By comparing the differences of indoor flow field distribution under five different working conditions, the optimal air supply parameters are obtained, that is, when the air supply temperature is $23{ }^{\circ} \mathrm{C}$ and the air supply speed is $3.3 \mathrm{~m} / \mathrm{s}$, the indoor temperature field and velocity field distribution are the best. The simulation results provide a theoretical basis for the setting of air supply parameters in the upper air supply room.
\end{abstract}

\section{Introduction}

With the development of economy, people's living standard has a qualitative leap, so the environment of daily life and work has higher requirements. Most of the buildings are decorated. As a necessary means to improve the building environment, air conditioning is now widely used in public buildings such as gymnasiums, cinemas, shopping malls, restaurants and office buildings. [1] Relevant literature shows that people in modern cities spend more than $80 \%$ of their time indoors every day. From this percentage, we can see that the comfort of the indoor environment has greatly affected the quality of people's life. Especially in the last decade, with the popularity of air conditioning, the indoor comfort of most countries in the world is far from the expected state, so the poor indoor comfort has become a topic of complaint for many people. More serious is that poor indoor environment will affect the health of personnel, such as headache, runny nose, nausea, inattention and so on. In medicine, we call these sick symptoms caused by indoor environment "sick building syndrome" (SBS). [2] Sick building syndrome not only reduces people's work efficiency, affects the quality of life, but also indirectly increases medical costs, causing economic losses to families. Therefore, enough attention must be paid to the comfort of air-conditioned rooms [3].

Therefore, this paper takes the air supply parameters of air-conditioned room as the starting point, completes the corresponding experimental analysis, and provides theoretical reference for the research of air-conditioned room comfort.

\section{Computational model}

The geometric model of the office room created in this simulation is $5 \mathrm{~m}$ in length, $4 \mathrm{~m}$ in width and $3 \mathrm{M}$ in height, and the air inlet size is $0.2 \mathrm{~m} \times 0.3 \mathrm{~m}$. On the basis of neglecting other heat sources, two heat sources, computer and human, are established. The geometric model of the upper air supply room is shown in Fig. 1, and the calculation grid models are shown in Fig. 2, Fig. 3 and Fig. 4, respectively.

\subsection{Geometric model and computational grid}

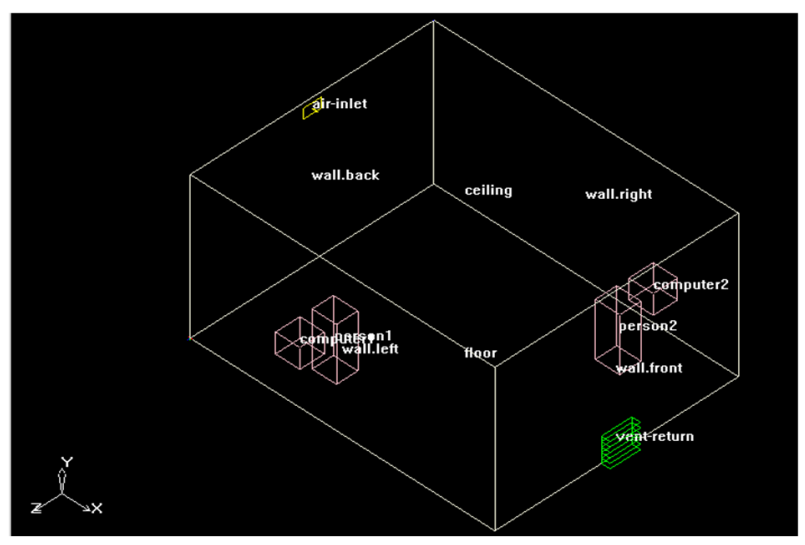

Fig. 1. Geometric model of upper air supply room

\footnotetext{
* Corresponding author: wyan ok@126.com
} 


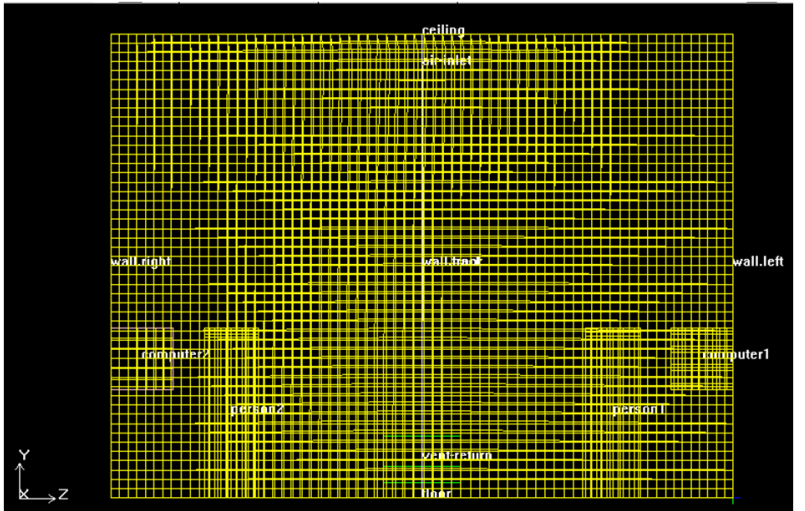

Fig. 2. Grid model of upper air supply room (x direction)

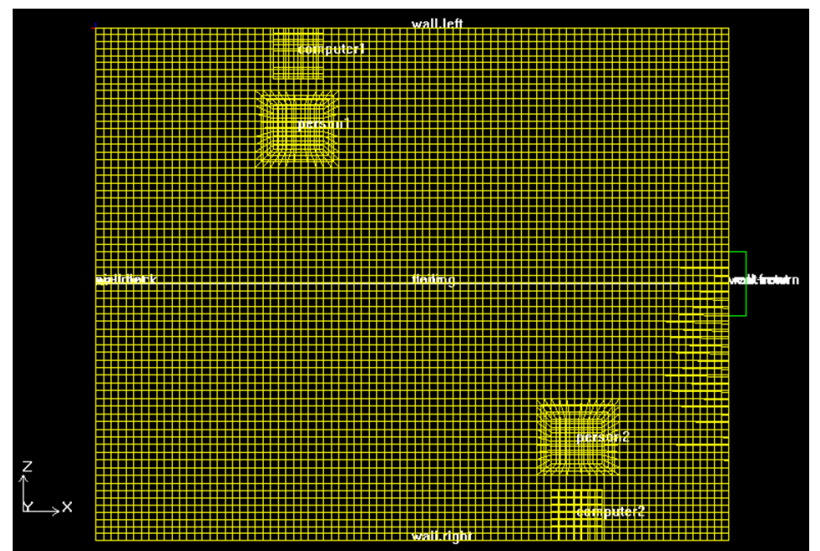

Fig. 3. Grid model of upper air supply room (Y direction)

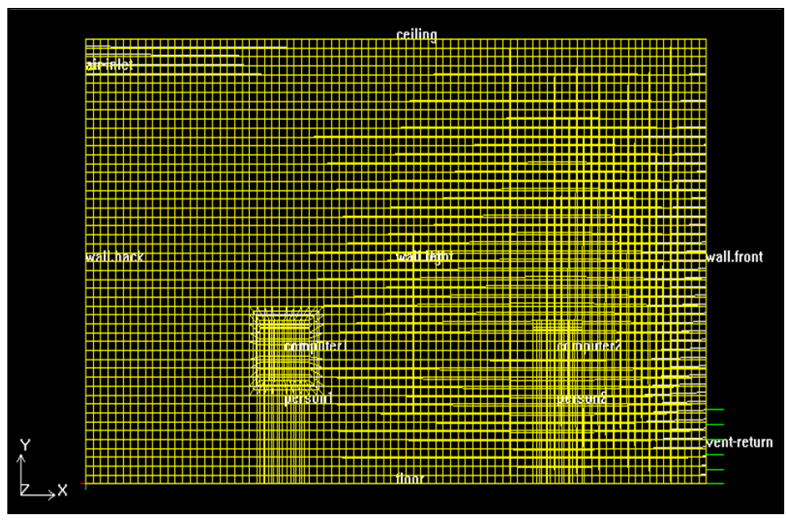

Fig. 4. Grid model of upper air supply room (z direction)

\subsection{Grid mathematical model}

The turbulent flow in the upper air supply room is unsteady, so the k-e two equation turbulence model is selected in the calculation. In this simulation, Euler Lagrange Model (k-e model) is used to simulate the discrete phase, and the movement of discrete phase is simulated by tracking the trajectory of particles [4].

The governing equation is as follows:

Energy conservation equation:

$$
\frac{\partial}{\partial t}(\rho e)+\nabla(\rho v \cdot e)=\nabla(k \cdot \nabla T)+q+\varepsilon
$$

Momentum conservation equation:

$$
\begin{gathered}
\frac{\partial(\rho u)}{\partial \tau}+\frac{\partial(\partial \mu \mu)}{\partial x}+\frac{\partial(\rho \theta \mu)}{\partial y}+\frac{\partial(\rho \mu \omega)}{\partial z}= \\
-\frac{\partial \rho}{\partial x}+\frac{\partial}{\partial x}\left(\lambda d i v u+2 \mu \frac{\partial u}{\partial x}\right)+\frac{\partial}{\partial y}\left[\mu\left(\frac{\partial v}{\partial x}+\frac{\partial u}{\partial y}\right)\right] \\
+\frac{\partial}{\partial z}\left[\mu\left(\frac{\partial v}{\partial z}+\frac{\partial u}{\partial x}\right)\right]+\rho F_{x}
\end{gathered}
$$

Mass conservation equation:

$$
\frac{\partial \rho}{\partial t}+\nabla(\rho v)=0
$$

Turbulent kinetic energy equation (k equation):

$$
\begin{gathered}
\frac{\partial}{\partial x}\left(\rho u_{i} u_{j}\right)=-\frac{\partial}{\partial x_{i}}\left(\frac{u_{i}}{\sigma_{\zeta}} \frac{\partial \kappa}{\partial x_{i}}\right)+u_{i}\left(\frac{\partial u_{i}}{\partial x_{j}}+\frac{\partial u_{j}}{\partial x_{i}}\right) \frac{\partial u_{j}}{\partial x_{i}} \\
-\rho \varepsilon+\beta g \frac{u_{i} \partial \tau}{p \gamma \partial x_{i}}
\end{gathered}
$$

Turbulent kinetic energy dissipation rate equation $(\varepsilon$ equation):

$$
\begin{array}{r}
\frac{\partial}{\partial x}\left(\rho u_{i} u_{j}\right)=-\frac{\partial}{\partial x_{i}}\left(\frac{u_{i}}{\sigma_{\zeta}} \frac{\partial \kappa}{\partial x_{i}}\right)+C_{1} u_{i} \frac{\varepsilon}{\kappa}\left(\frac{\partial u_{i}}{\partial x_{j}}+\frac{\partial u_{j}}{\partial x_{i}}\right) \\
+C_{2} \frac{\varepsilon^{2}}{\kappa}+C_{3} \beta g \frac{u_{i} \partial \tau}{p \gamma \partial x_{i}}(i, j=1,2,3)
\end{array}
$$

The expression of turbulent viscosity coefficient is as follows

$$
u_{i}=\frac{C_{u} C_{D} \rho \kappa^{2}}{\varepsilon}
$$

Where: $\kappa$ - turbulent kinetic energy of fluid, J;

$P$ - time average pressure, $\mathrm{Pa}$;

$P r$ - Prandtl number;

$\tau$ - time constant, s;

$u_{i}$ - velocity component;

$\varepsilon$ - turbulent energy dissipation, \%;

$\rho$ - fluid density, $\mathrm{kg} / \mathrm{m}^{3}$;

$\beta$ - fluid volume expansion coefficient

\subsection{Geometric model and computational grid}

When the temperature of air supply outlet is between 18$25{ }^{\circ} \mathrm{C}$ and the speed of air supply outlet is between 2.5 $3.8 \mathrm{~m} / \mathrm{s}$, the working area has a good sense of comfort. Therefore, based on this standard, five different working conditions are selected from the interval to analyze and compare the differences of indoor flow field distribution under different working conditions, and the optimal air supply parameters are obtained [5]. The following five working conditions are specially simulated in this simulation, as shown in Table 1.

Table 1. Simulation conditions

\begin{tabular}{|c|c|c|}
\hline $\begin{array}{c}\text { Working } \\
\text { condition }\end{array}$ & $\begin{array}{c}\text { Supply air } \\
\text { temperature }(\mathrm{K})\end{array}$ & $\begin{array}{c}\text { Supply air temperature } \\
\text { and speed }(\mathrm{m} / \mathrm{s})\end{array}$ \\
\hline A1 & 298 & 2.5 \\
\hline A2 & 298 & 3 \\
\hline A3 & 298 & 3.5 \\
\hline A4 & 297 & 3.5 \\
\hline A5 & 296 & 3.3 \\
\hline
\end{tabular}




\section{Simulation of temperature field and velocity field}

\subsection{A1 and A2 working conditions}

For A1 and A2 conditions, the supply air temperature is $25{ }^{\circ} \mathrm{C}$, only the change of supply air speed, so the temperature field and velocity field of the two conditions are compared and analyzed.

\subsubsection{The temperature field of Y-section 1 meter} above the ground during sitting is shown in Fig. 5 and Fig. 6

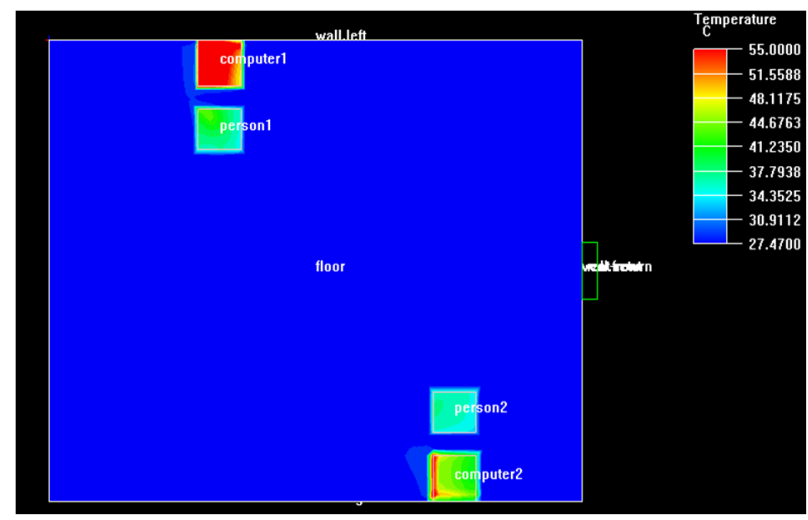

Fig. 5. Temperature field of section at $\mathrm{y}=1 \mathrm{~m}$ under $\mathrm{A} 1$ condition

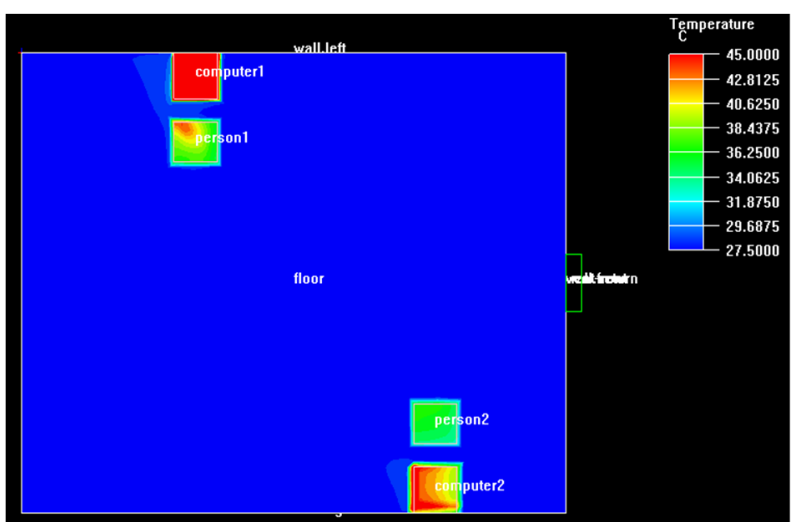

Fig. 6. Temperature field of section at $\mathrm{y}=1 \mathrm{~m}$ under $\mathrm{A} 2$ condition

There is little difference between Fig. 5 and Fig. 6. Under the two conditions, most of the room temperature is between $29{ }^{\circ} \mathrm{C}$. The minimum temperature and maximum temperature of condition 2 are the same as that of condition 1 , and the maximum temperature is $10{ }^{\circ} \mathrm{C}$ lower than that of condition 1 . From the difference of the maximum temperature between the two conditions, it can be concluded that the temperature field of $\mathrm{Y}$ section in condition 2 is better than that in condition 1 .
3.1.2 The temperature field of $Y$-section at $1.5 \mathrm{~m}$ above the ground during sitting is shown in Fig. 7 and Fig. 8

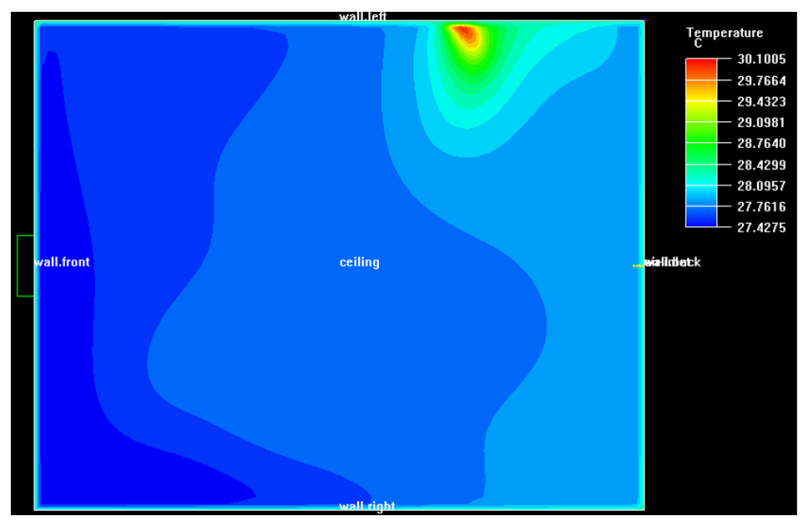

Fig. 7. Temperature field of section at $y=1.5 \mathrm{~m}$ under $\mathrm{A} 1$ condition

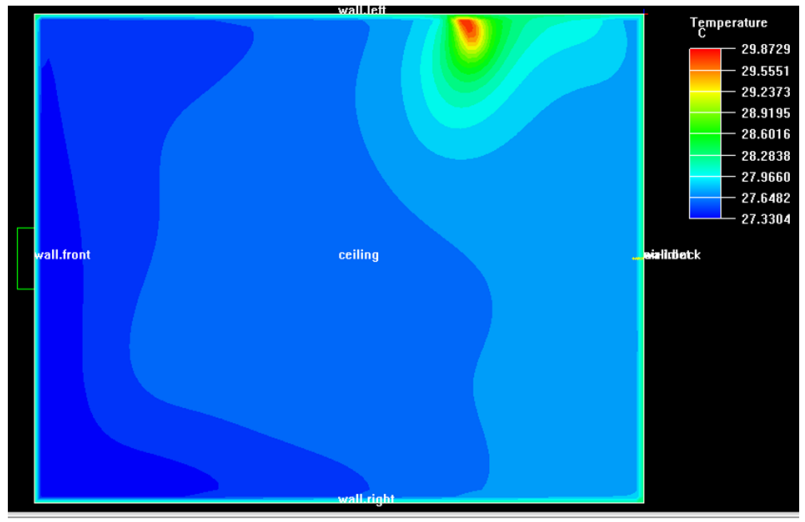

Fig. 8. Temperature field of section at $y=1.5 \mathrm{~m}$ under $\mathrm{A} 2$ condition

Comparison between condition A2 and condition A1: the maximum temperature of condition $\mathrm{A} 2$ is $0.5{ }^{\circ} \mathrm{C}$ lower than that of the first two conditions, but for the overall temperature of condition 2, the temperature in some places in the temperature field is higher than $28{ }^{\circ} \mathrm{C}$, that is, higher than the comfort of human body, so when the temperature is $25{ }^{\circ} \mathrm{C}$, it can not meet the comfort of human body.

3.1.3 The velocity field of $z$ plane under $A 1$ and $A 2$ conditions is shown in Fig. 9 and Fig. 10

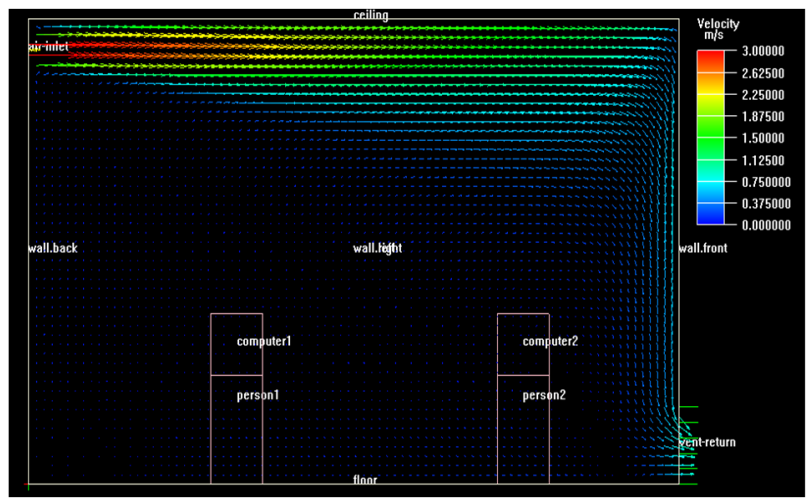

Fig. 9. Velocity field of section in z plane under A1 condition 


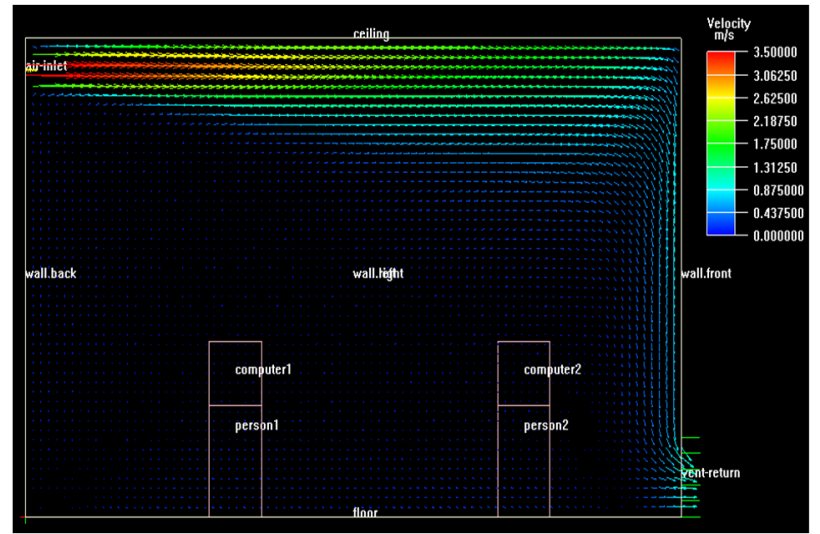

Fig. 10. Velocity field of section in z plane under A2 condition

Comparison between working condition A2 and working condition A1: it can be seen that after changing the speed twice, when the air inlet speed is $3.5 \mathrm{~m} / \mathrm{s}$, the flow velocity around the human body and computer becomes larger, but it is still within the comfort range of human body. For the z-plane temperature field under the two conditions, only the maximum velocity of the two conditions changes, and the others change little.

\subsubsection{The velocity field distribution when $y$ is equal} to $1 \mathrm{~m}$ in $A 1$ and $A 2$ working conditions room is shown in Fig. 9, and Fig. 10

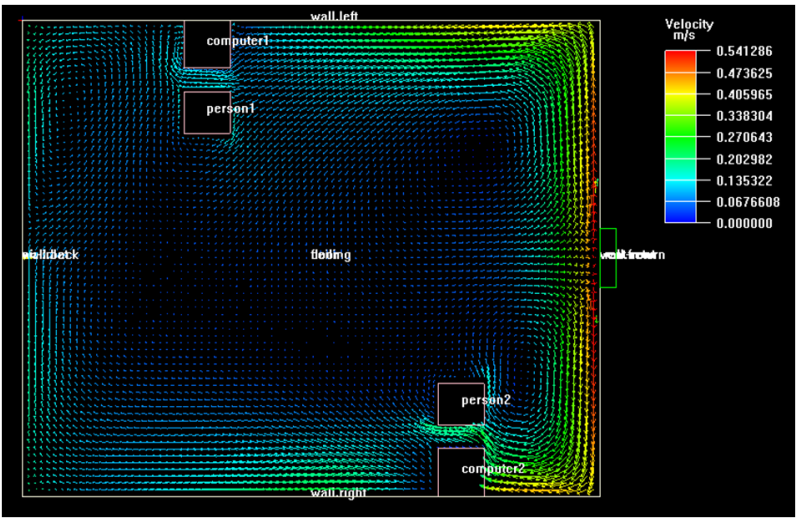

Fig.11. Velocity field of section at $\mathrm{y}=1 \mathrm{~m}$ under $\mathrm{A} 1$ condition

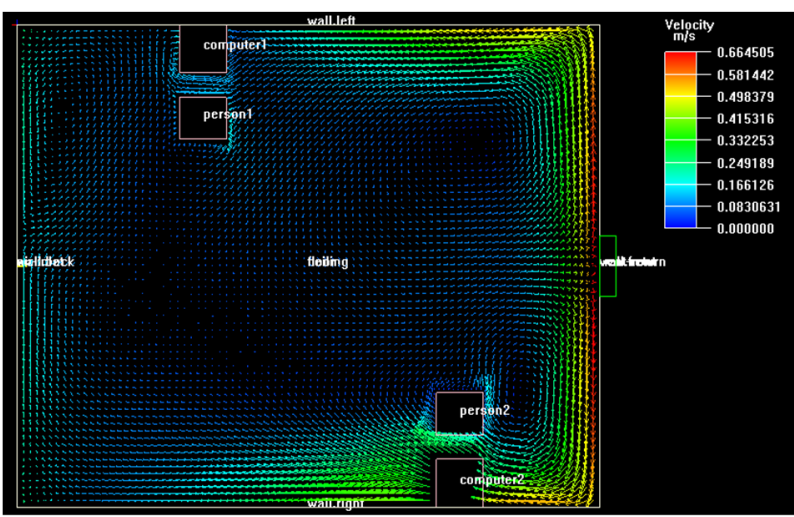

Fig. 12. Velocity field of section at $\mathrm{y}=1 \mathrm{~m}$ under $\mathrm{A} 2$ condition

Comparison between working condition A2 and working condition A1: after changing the speed twice, when the air inlet speed is $3.5 \mathrm{~m} / \mathrm{s}$, the velocity around the human body and the computer is between $0.17 \mathrm{~m} / \mathrm{s}$ and $0.3 \mathrm{~m} / \mathrm{s}$, and the human body feels basically comfortable within this velocity range, so the analysis of the velocity field conforms to the human body's comfortable feeling, but for the velocity field of working condition 3 , the temperature around the human body and the computer is still a little high.

\subsubsection{The temperature and speed of condition 3} and 4 are different, so condition 3 and 4 are discussed separately.

(1) The temperature field of $Y$ section $1 \mathrm{~m}$ above the ground when the human body is sitting is shown under A3 condition in Fig. 13

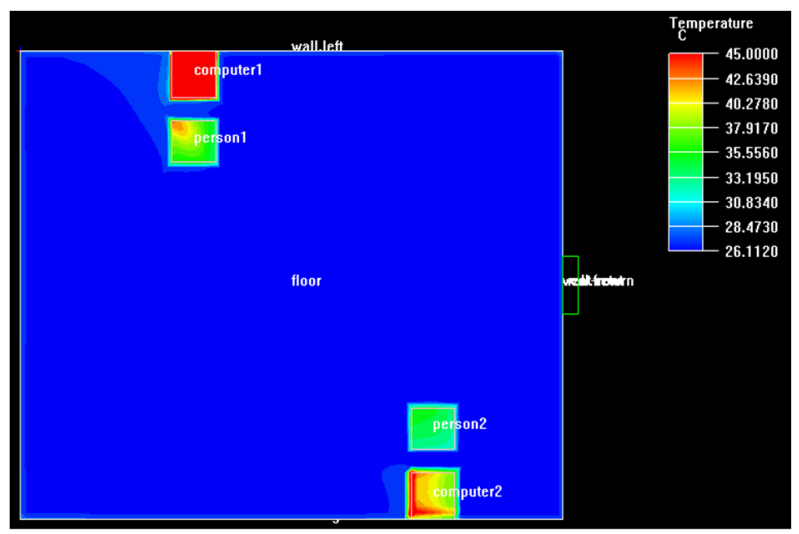

Fig. 13. Temperature field of $y=1 \mathrm{~m}$ section

(2) The temperature field of $Y$ section $1.5 \mathrm{~m}$ above the ground when the human body is sitting is shown under A3 condition in Fig. 14

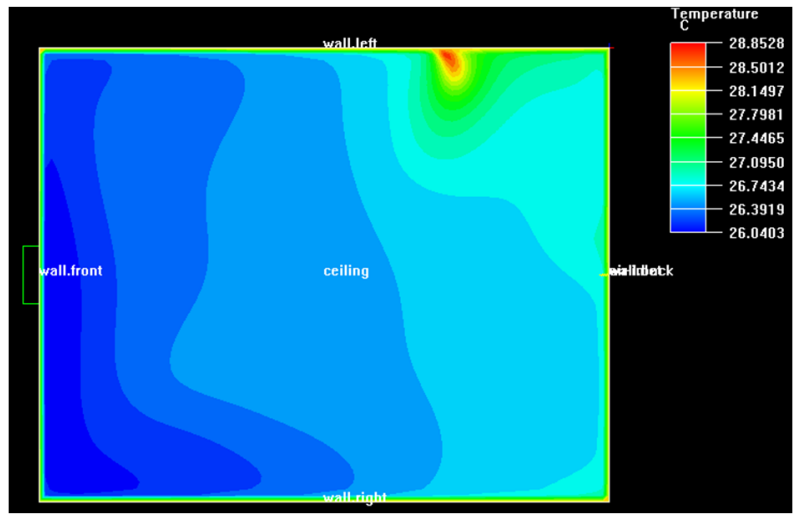

Fig. 14. Temperature field of $y=1.5 \mathrm{~m}$ section

(3) The velocity field of air supply mode under A3 is shown in Fig. 15 and Fig. 16 


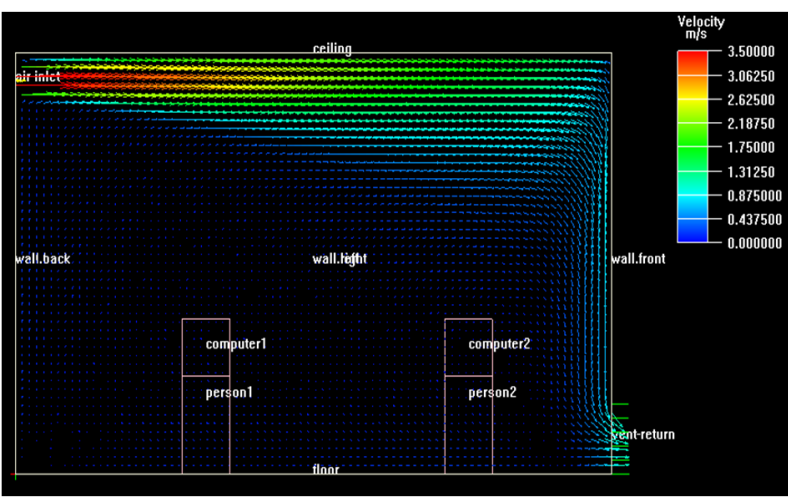

Fig. 15. Velocity field of $\mathrm{z}$ section

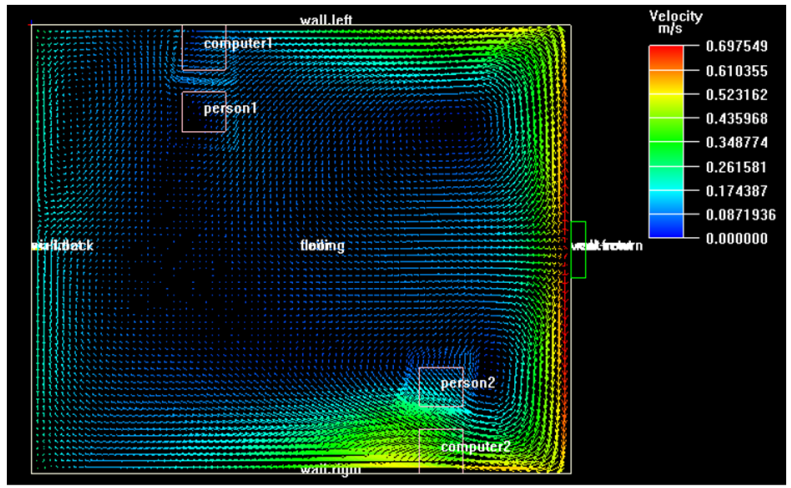

Fig. 16. Velocity field of $y=1 \mathrm{~m}$ section

Comparing condition 3 with condition 2: the air supply speed of condition 3 is consistent with that of condition 2, so the change of velocity field is not particularly obvious. However, it can be seen from the figure that the wind speed around the human body at the right wall reaches $0.35 \mathrm{~m} / \mathrm{s}$, when the wind speed around the human body reaches 0.33 , the human body will feel uncomfortable, and the wind speed can blow the tissue paper, and the wind speed around the human body at the left wall is in the range of $0.08-0.26 \mathrm{~m} / \mathrm{s}$. The human body feels comfortable.

(4) The temperature field of $Y$ section one meter above the ground when the human body is sitting still is shown under A4 condition in Fig. 17 and Fig. 18.

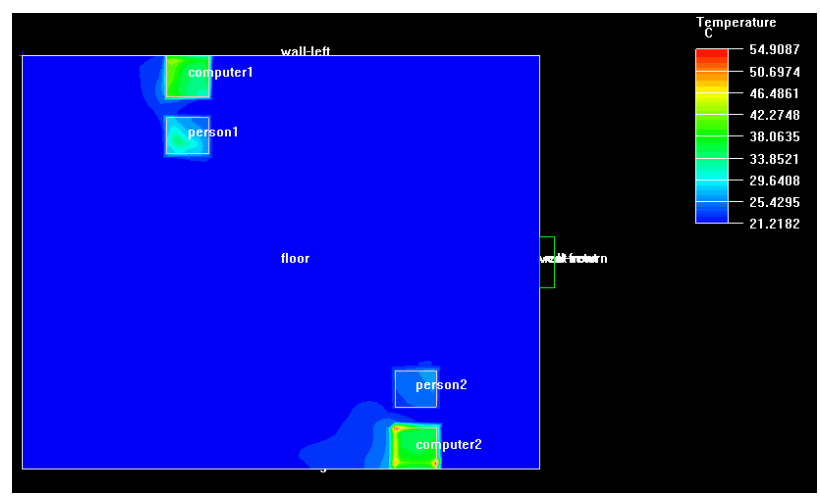

Fig. 17. Temperature field of $y=1 \mathrm{~m}$ section

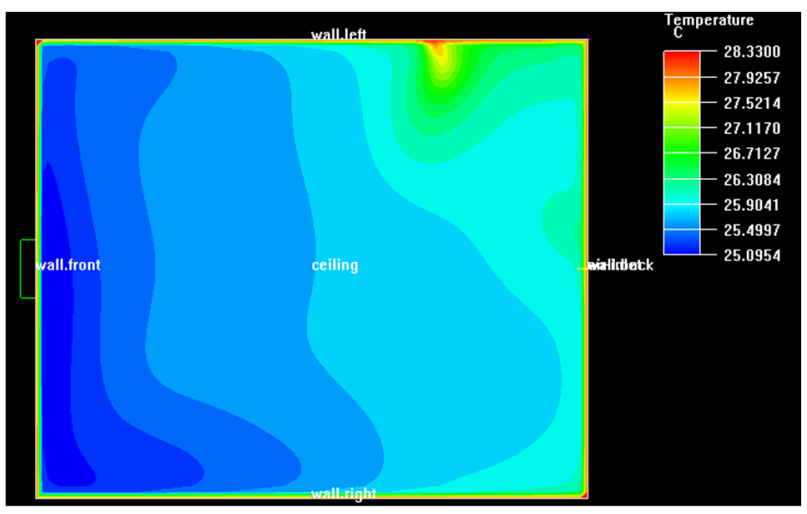

Fig. 18. Temperature field of $y=1.5 \mathrm{~m}$ section

It can be seen from Figure 18 that the temperature around two people is in the range of $25-33{ }^{\circ} \mathrm{C}$, and most of the area is between $29{ }^{\circ} \mathrm{C}$, which is in line with the comfort range of human body. Compared with the previous working conditions, the temperature field of this working condition is the optimal velocity field. Whether it is resting or working, the temperature field conforms to the comfortable temperature of human body.

(5) The velocity field of air supply mode under A4 condition is shown in Fig. 19 and Fig. 20.

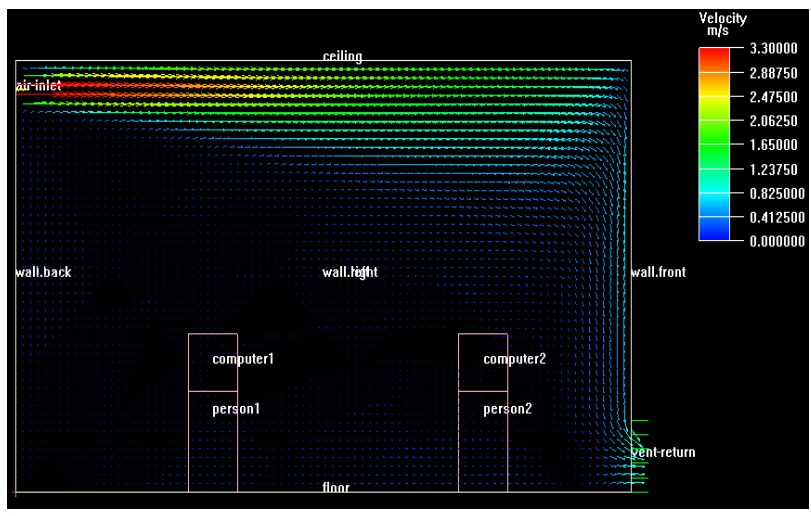

Fig. 19. Velocity field of $z$ section

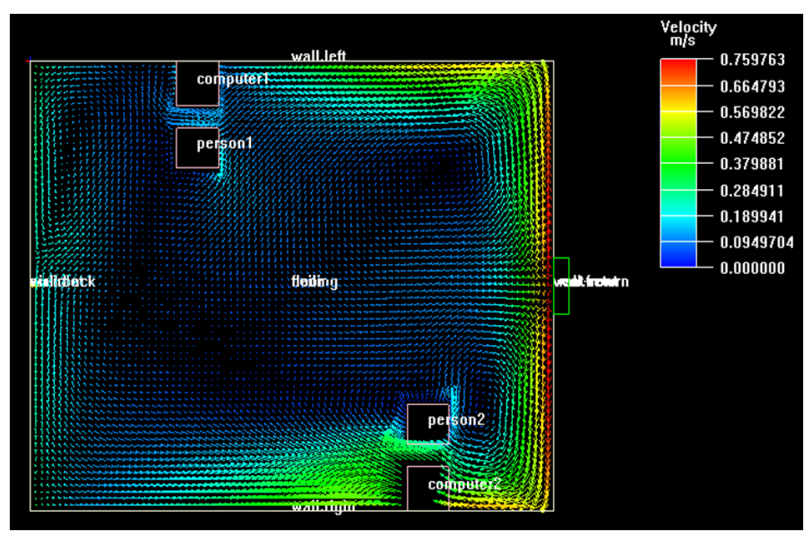

Fig.20. Velocity field of $\mathrm{y}=1 \mathrm{~m}$ section

It can be seen from the figure that for the right wall, the wind speed around the human body is about $0.28 \mathrm{~m} / \mathrm{s}$, and the human body basically keeps comfortable at this speed. For the left wall, the wind speed around the human body is about $0.18 \mathrm{~m} / \mathrm{s}$, which is basically in the ideal comfortable wind speed. Therefore, when the 
supply air temperature is $23{ }^{\circ} \mathrm{C}$ and the supply air velocity is $3.3 \mathrm{~m} / \mathrm{s}$, the temperature field and velocity field of the upper supply air room are the best.

\section{Conclusion}

In the simulation process, for condition 1 and condition 2, the air supply temperature of the three conditions is the same. After changing the air supply speed, the temperature field and velocity field of the three conditions are compared and analyzed. It is obvious that the air supply speed is relatively high near the air supply outlet, and the surrounding temperature of human body and computer is higher, which can not meet the requirements of human comfort. Although the air supply parameters of condition 3 are different from those of condition 1 and 2, they can not meet the requirements of human comfort. However, condition 4 can alleviate the problem of high temperature around the human body and computer to the greatest extent. The temperature around the human body is in the range of $25-33{ }^{\circ} \mathrm{C}$, and most of the area is between $29{ }^{\circ} \mathrm{C}$. Whether it is resting or working, the temperature is in line with the comfortable temperature of the human body. The wind speed around the human body is about $0.18 \mathrm{~m} / \mathrm{s}$, which is basically in the ideal comfortable wind speed of the human body, that is, the temperature field and speed field of condition 4 are the best.

\section{Acknowledgments}

This paper is supported by R\&D center of building energy saving engineering technology of Shandong Huayu University of Technology.

\section{References}

1. Sun Jianmei, Liu Yunzhao. Influence of air supply mode on indoor comfort of an office building [J]. Journal of Shandong Institute of architectural engineering, (2015)

2. Cao zhuochao, He Jiapeng, Zhou Ru. Influence of different air supply modes on thermal comfort of building environment [D]. Building thermal ventilation and air conditioning, (2016)

3. Zhao Fuyun, Cheng pan, Zhang Dongdong. Multi index numerical evaluation of indoor air environment under displacement ventilation and mixed ventilation [D]. School of power and machinery, Wuhan University, (2018)

4. Ma Jianlei. Simulation of indoor thermal comfort under three main ventilation and air conditioning modes [D]. Chongqing University, (2015)

5. Chen Huanxin, Liu Rui, Yang Peizhi. Air Distribution and thermal comfort in air-conditioned passenger cars $[\mathrm{J}]$. Refrigeration and electrical machinery, 2002,23(85) : 18-20. 